\title{
Patterns and outcome of respiratory disease among adult in-patients, in Abuja-Nigeria
}

\author{
Akor, A.A. ${ }^{1}$, Idenyi E. ${ }^{1}$, Hilary C. ${ }^{1}$, Akor, B.O. $^{2}$
}

\begin{abstract}
Objectives: Respiratory disease is a leading cause of morbidity and mortality worldwide. Most of the deaths will occur in low resource countries like Nigeria. There is limited data on the burden of these respiratory diseases.
\end{abstract}

Methods: A retrospective study of three hundred and seventy-seven (377) cases was carried out. Case selection was based on review by at least a specialist pulmonologist. Other data were retrieved with the help of questionnaire for analysis.

Results: Respiratory diseases accounted for about $10.4 \%$ of hospital admissions at the medical emergency of the hospital. Pulmonary tuberculosis (PTB) (40.3\%) and acute lower respiratory tract infections (ALRTI) $(27.9 \%$ ) were the major presentation. More deaths occurred from PTB (51.6\%), with HIV and diabetes mellitus been the major comorbidities commonly associated with the disease presentation.

Conclusion: The burden of respiratory diseases is substantial, with communicable diseases such as PTB and ALRTI are leading in terms of inpatient presentation. HIV disease is the main condition commonly associated with morbidity and mortality.

Keywords: respiratory diseases, burden, outcome

\section{*Corresponding author}

AkorA.A.

http://orcid.org/0000-0002-6955-5392

Email address Alexander.agada@uniabuja.edu.ng

${ }^{1}$ Department of Internal Medicine, University of Abuja Teaching Hospital, Gwagwalada, Nigeria

${ }^{2}$ Department of Family Medicine, University of Abuja Teaching Hospital, Gwagwalada, Nigeria 


\title{
Profils et évolution des maladies respiratoires chez les patients adultes hospitalisés à Abuja-Nigeria
}

\author{
*Akor, A.A. ${ }^{1}$, Idenyi E. ${ }^{1}$, Hilary C. ${ }^{1}$, Akor, B.O. ${ }^{2}$
}

\section{Resume}

Objectifs: Les maladies respiratoires sont l'une des principales causes de morbidité et de mortalité dans le monde. La plupart des décès surviendront dans des pays à faibles ressources telles que le Nigeria. Les données sur le fardeau de ces maladies respiratoires sont limitées.

Méthodes: Une étude rétrospective de trois cent soixante dix sept (377) cas a été réalisée. La sélection des cas était basée sur l'examen d'au moins un pneumologue spécialisé. D'autres données ont été récupérées à l'aide d'un questionnaire pour analyse.

Résultats: Les maladies respiratoires représentaient environ 10,4\% des hospitalisations à l'urgence médicale de l'hôpital. La tuberculose pulmonaire (PTB) (40,3\%) et les infections aiguës des voies respiratoires inférieures (ALRTI) $(27,9 \%)$ constituaient la présentation principale. Les décès dus à la TBP étaient plus fréquents $(51,6 \%)$, le VIH et le diabète sucré constituant les principales comorbidités couramment associées à la maladie.

Conclusion: le fardeau des maladies respiratoires est considérable. Les maladies transmissibles telles que la PTB et les ALRTI sont en tête en termes de présentation des patients hospitalisés. Le VIH est la principale affection couramment associée à la morbidité et à la mortalité.

Mots-clés: maladies respiratoires, fardeau, résultats

\section{*Auteur principal}

AkorA.A.

http://orcid.org/0000-0002-6955-5392

Email address Alexander.agada@uniabuja.edu.ng

${ }^{1}$ Department of Internal Medicine, University of Abuja Teaching Hospital, Gwagwalada, Nigeria

${ }^{2}$ Department of Family Medicine, University of Abuja Teaching Hospital, Gwagwalada, Nigeria

Research Journal of Health Sciences subscribed to terms and conditions of Open Access publication. Articles are distributed under the terms of Creative Commons Licence (CC BY-NC-ND 4.0). (http://creativecommons.org/licences/by-nc-nd/4.0).

http://dx.doi.org/10.4314/rejhs.v7i3.5 


\section{INTRODUCTION}

Respiratory diseases are responsible for a major burden of morbidity and mortality globally, with conditions such as tuberculosis and acute lower respiratory tract infections being the most important in world health terms (1). The increasing prevalence of allergy, asthma, chronic obstructive pulmonary disease (COPD) and lung cancers contributes to the overall burden of chronic respiratory disease in the community (2, 3 ). This situation is made worse by the increasing number of cigarette smokers worldwide; ensuring a growing burden of tobacco-related respiratory conditions. The risk factor for developing these respiratory diseases are potentially preventable. Reduction in tobacco smoking, and improvement in the air quality indoor and at workplace are key to controlling these factors that are associated with reducing the burden of the respiratory diseases. An estimated 65million, 334million, 10.4million,1.6million; suffer from COPD, asthma, tuberculosis and lung cancers respectively (3). The global impact of these main respiratory diseases is massive, devastating, and costly. They are the leading causes of death, disability, and suffering, especially in the most disadvantaged poor health resource countries (4). According to the World Health Organization estimates, respiratory diseases account for 9 million deaths (one-sixth of the global total) and one-tenth of the disabilityadjusted life-years (DALYs) lost worldwide (3). In addition to these common respiratory diseases there are several others like sleep-disordered breathing, pulmonary hypertension and occupational lung diseases whose burden are substantial but less well quantified. In most developing countries including Nigeria, the burden of respiratory disease is largely unknown; however, it appears to be on the increase (5). Respiratory infections, particularly $\mathrm{TB}$ and bacterial pneumonia, are the major causes of death in adults and children. (5). This study was designed to determine the prevalence and pattern of respiratory disease admission in a tertiary health care facility in the north central part of Nigeria.

\section{METHODS AND MATERIALS Study background}

The study location was University of Abuja Teaching Hospital (UATH) Gwagwalada. The hospital is a tertiary health facility with 350 bed spaces, located in one of the Federal Capital Territory (FCT) area council- Gwagwalada. Gwagwalada lies between $8^{\circ} 56^{\prime} 29^{\prime \prime}$ North and $7^{\circ}$
5' 31" East. It has an area of $1,043 \mathrm{~km}^{2}$.The Federal Capital Territory had a projected population of 1,406,239 inhabitants in the year 2006, of which 157770 (11.22\% approximately) inhabitants reside in Gwagwalada. The hospital provides health care services to the inhabitants of Abuja and neighboring states.

\section{Study design}

This was a retrospective study conducted from $1^{\text {st }}$ January 2016 to $31^{\text {st }}$ December 2018 (Thirty-six months).

\section{Methods}

A modified version of the chronic respiratory disease questionnaire (6) was used to obtain information on socio-demographic characteristics, comorbidities and respiratory symptoms of the patients. Patient selection was based on history, physical examination and investigation review by a specialist pulmonologist. Patients finally selected were those who are judged to have a respiratory medical condition. Three hundred and ninetyeight cases were reviewed in the study. Three hundred and seventy-seven (377) met the inclusion criteria, twemty $=$ one hospital folders had incomplete records and were eliminated in the final analysis. Those who had a confirmed respiratory disease and were managed defined outcome and either discharged home from the ward or died.

\section{Data Analysis}

Data from the retrieved questionnaires were coded, entered and analyzed using Statistical Package for Social Sciences (SPSS) version 20. Frequency distribution of variables were generated. Independent and dependent variables were cross tabulated to determine degree of association. Comparison between different groups was done using Fisher's exact test, Pearson Chi-Square, Student t-test and test of correlation was performed using Spearman correlation test. Confidence interval was $95 \%$ and the $\mathrm{p}$ value less than 0.05 was considered significant.

\section{RESULTS}

Out of the three hundred and ninety-eight (398) cases reviewed, three hundred and seventyseven (377) of them met the selection criteria. The total number of patients admitted during the study period was three thousand, six hundred and eighty-six, which give a prevalence of respiratory diseases to be about $10.3 \%$. There were more 
women admitted than the men, with a male to female ratio of $1: 12$ the mean age of the study population was $44.4 \pm 16.5$. The communicable and infectious diseases accounted for most of the respiratory conditions seen within this period. Pulmonary tuberculosis was the major presentation $40.3 \%$ (152), with nearly equal gender distribution and the mean age of presentation was $41.3 \pm 15.1$ years, this is closely followed by pneumonia with a mean age of presentation of $46.4 \pm 18.1$ years. Among the noncommunicable diseases Asthma and COPD were the predominant respiratory condition, with prevalence rates of $16.0 \%$ and $8.2 \%$ respectively. See table 1 for more details

In terms of the expected outcome, we recorded at least thirty-one deaths. More mortality occurred from pulmonary tuberculosis $51.6 \%$ and Bronchogenic Carcinoma 16.1\%. We report five (5) patients with bronchogenic Carcinoma; 4 of them had histologic diagnosis of alveolar cell carcinoma, mean age of presentation was 61 years, no history of cigarette smoke and all of them were women. We had one case of squamous cell carcinoma in a 49 years old man with 20 pack years of cigarette smoked. table 2 shows more details.

Table 3 shows a cross tabulation of morbidity of the respiratory disease and comorbidity. HIV/AIDS, Diabetes Mellitus and lung malignancy were the major comorbidities observed with frequency of $97(25.7 \%), 17$ $(4.5 \%)$ and $4(0.01 \%)$ of the overall cases reviewed. In a similar fashion HIV/AID was the most frequent comorbidity associated with pulmonary tuberculosis. (See table 3 for details)

\section{DISCUSSION}

Respiratory diseases contribute greatly to the health burden of the people. This is evidenced by the large proportion of medical emergencies which are of pulmonary origin. Our study found that $10.4 \%$ of medical emergencies were of respiratory origins. This is similar to a prevalence of $10.2 \%$ as recorded in another study done in same geographic location (7).

The mean age of the study group was $44.4 \pm 16.5$ years with a slight female predominance which is comparable to "a M:F ratio of 1:1.2" which was however in contrast to the sex distribution of other studies which found a slight male predominance $(7,9,10)$. The reason for this may be as a result of improving health seeking behavior of females in our locality.

Of the respiratory emergencies, the commonest were PTB $(40.3 \%)$, pneumonia (27.9\%), asthma (16.0\%) and AECOPD (8.2\%).
Bronchogenic CA was the least $(1.6 \%)$. The prevalence of PTB (40.3\%) was similar to $66.8 \%$ found in a study in eastern-southern part of the country (11), which was also followed by pneumonia $(24.9 \%)$, which again was close to our finding of $27.9 \%$. PTB predominance were also noted elsewhere in India and Congo, 54.6\% and $52.08 \%$ respectively $(9,12)$. This finding is not surprising as the communicable diseases and infections still predominate in sub-Saharan Africa where poverty, overcrowding play a major role in the distribution of diseases. However, Desalu et al found a contrasting pattern in which there was pneumonia predominance with a prevalence of $34.5 \%$ followed by PTB (29.4\%), asthma and AECOPD in that order (7). Whether this was as a result of his previous study in which he found that seasonal variations affect pattern of respiratory disease is unknown. He observed that during dry seasons there is pneumonia predominance (8). The frequency of noncommunicable diseases like COPD and lung cancer is still low in this region. This may be because we do not have screening facility, the capacity to make prompt and accurate diagnosis in most of our hospital.

Our study recorded 31 deaths which put the overall mortality rate at $8.2 \%$. Twenty-four (24) hours mortality rates of $7.4 \%$ and $7.1 \%$ were also recorded in similar studies in the same geographical region $(7,10)$. Whereas elsewhere, overall mortality was as high as $13.5 \%$ and $14.7 \%$ $(8,11)$. PTB recorded the highest mortality of $51.6 \%$, followed by bronchogenic CA $16.1 \%$. Both pneumonia and AECOPD showed rates of $12.9 \%$. The PTB mortality rate was higher than $44.4 \%$ that was recorded in a previous study in the same location (7). Mortality rates as high as $57.04 \%$ were recorded elsewhere (12). This shows that PTB is a major cause of mortality in our region and the world at large. This may be due to the reported coexistence of PTB with other chronic respiratory diseases which may not be immediately apparent at presentation (13). In this study, malignancy contributed the highest percentage of mortality among the noncommunicable diseases. This is not an unusual finding as most of them often present to our facility at the terminal stage of the disease after having tried many hospitals and or due to financial constraints.

Of the comorbidities present, we observed that HIV was the commonest medical condition frequently associated with the patients. This was followed by DM and lastly Malignancy. HIV predominant coexistence with respiratory diseases is of importance as it causes increased 
mortality on the patients. Other studies also noted $\mathrm{HIV}$ as the commonest comorbidity in respiratory diseases $(10,11,12)$. Respiratory diseases were predicted to occur more in HIV patients especially with reducing CD4 count (14).

It is worthy of note that $74.2 \%$ of the HIV comorbidities were associated with PTB. This buttresses the fact that there is high incidence of HIV/PTB coexistence and this ultimately yields higher mortality $(15,16)$.

\section{CONCLUSION}

Respiratory diseases contribute ample percentage of medical in-patient admissions. Of the respiratory morbidity, $\mathrm{PTB}$ is the most occurring in our center and is often associated with HIV comorbidity. The resultant effect is a high patient mortality rate in those group of patients. Therefore, high index of suspicion of PTB/HIV coexistence must be applied in the respiratory emergency room to ensure early diagnosis and prompt institution of appropriate treatment to avert mortality. Finally, more resources and future research should be directed at combatting the risk factors of these diseases.

Ethical approval- not applicable

Acknowledgement: We thank Dr Martina Abutu who assisted in the initial ground work of gathering all the cases for review and also the head of department of internal medicine university of Abuja teaching hospital who encouraged us to carry the study.

Conflict of interest: We declare no competing interest

\section{REFERENCES}

1. Ferkol T, Schraufnagel D. The global burden of respiratory disease. Annal America Thoracic Society. 2014;11(3):404-6.

2. Salciccioli Justin D, Marshall Dominic C. Shalhoub Joseph, Maruthappu Mahiben, De Carlo Giuseppe, Chung Kian Fan et al. Respiratory disease mortality in the United Kingdom compares with EU15+ countries in 1985-2015: observational study BMJ2018; 306 : k4680

3. Forum of International Respiratory Societies. The Global Impact of Respiratory Disease Second Edition. Sheffield, European Respiratory Society, 2017.
4. Ahmed R, Robinson R, Mortimer K. The epidemiology of noncommunicable respiratory disease in sub-Saharan Africa, the Middle East, and North Africa. Malawi Medical Journal. 2017;29(2):203-211.

5. Akanbi MO, Ukoli CO, Erhabor GE, Akanbi FO, Gordon SB. The burden of respiratory disease in Nigeria. African Journal Respiratory Medicine. 2009; 4:10-17.

6. Jones PW, Quirk FH, Baveystock CM. The St George's respiratory questionnaire. Respiratory medicine. 1991; 85:25-31.

7. Desalu OO, Ojo OO, Busari OA, Fadeyi A. Pattern of respiratory diseases seen among adults in an emergency room in a resource-poor nation health facility. Pan African medical 2011;9:24

8. Desalu OO. Seasonal variation in hospitalization for respiratory diseases on the tropical rain forest of south western Nigeria. Nigeria Postgraduate Medical Journal 2011;18(1),39-43.

9. Sachdeva R, Sachdeva S, Gupta KM. Pattern and outcome of patients discharged from chest ward of a university hospital. Medical Journal of Dr. D. Y. Patil Vidyapeeth Univ 2013; 6:240-244.

10. Adeniyi BO, Ilesanmi OS, Fadare SO, Akinyugha AO, Erhabor GE. Pattern of respiratory diseases among patients seen at the emergency unit of a tertiary health facility in South-West Nigeria. Nigerian Journal of Health Sciences. 2016;16(1):22.

11. Victor AniediUmoh, AkaninyeneOtu, Henry Okpa, and Emmanuel Effa, "The Pattern of Respiratory Disease Morbidity and Mortality in a Tertiary Hospital in Southern-Eastern Nigeria," Pulmonary Medicine, 2013;2013:581973.

12. Mbuosa J. Respiratory diseases at hospital in Brazzaville Congo. Revue de pneumologue Clinique 1990;46(2), 61-65.

13. Byrne AL. Tuberculosis and chronic respiratory diseases; a systemic review. International journal of infectious disease 2015;32,138-146.

14. Wallace JM, Hansen NI, Lavange L, Glassroth J, Browdy BL, Rosen MJ, Fouman D. Respiratory disease trends in the pulmonary complications of HIV infection study cohort. American Journal of Respiratory and critical care medicine, 1997;155(1):72-80.

15. Miller R. HIV- associated respiratory diseases. The lancet 1996;348(9023), 307-312.

16. Kishamawe, C., Rumisha, S. F., Mremi, I. R., Bwana, V. M., Chiduo, M. G., Massawe, I. S. and Mboera, L. E. (2019), Trends, patterns and causes of respiratory disease mortality among inpatients in Tanzania, 2006-2015. Tropical Medicine and International Health, 24: 91-100. 
Table 1: Distribution of disease with age and gender

\begin{tabular}{lllll}
\hline Diagnosis & Age mean (SD) & Female n $(\%)$ & Male n $(\%)$ & Total n (\%) \\
\hline Pneumonia & $46.4 \pm 18.1$ & $57(28.6 \%)$ & $48(27.4)$ & $105(27.9 \%)$ \\
Pulmonary tuberculosis & $41.3 \pm 15.1$ & $78(38.6 \%)$ & $74(42.3 \%)$ & $152(40.3 \%)$ \\
Acute severe asthma & $40.0 \pm 16.0$ & $33(16.3 \%)$ & $27(15.4 \%)$ & $60(16.0 \%)$ \\
AECOPD & $57.8 \pm 13.5$ & $13(6.4 \%)$ & $18(10.3 \%)$ & $31(8.2 \%)$ \\
Pleural effusion & $44.2 \pm 12.5$ & $11(5.4 \%)$ & $6(3.4 \%)$ & $17(4.5 \%)$ \\
Bronchogenic CA & $60.7 \pm 10.2$ & $4(2.0 \%)$ & $2(1.1 \%)$ & $6(1.6 \%)$ \\
Pulmonary embolism & $42.2 \pm 10.1$ & $6(3.0 \%)$ & $0(0.0)$ & $6(1.6 \%)$ \\
Total & $44.4 \pm 16.5$ & $202(53.6)$ & $175(46.4)$ & $377(100 \%)$ \\
\hline
\end{tabular}

$\mathrm{SD}=$ standard deviation, $\mathrm{AECOPD}=$ acute exacerbation of chronic obstructive pulmonary disease, $\mathrm{CA}=$ carcinoma, $\mathrm{n}=$ frequency

Table 2: Diagnosis of in-patients and outcome

\begin{tabular}{llll}
\hline Diagnosis & Discharged n (\%) & & \\
& & Died n (\%) & Total n (\%) \\
\hline Pneumonia & $101(29.2)$ & $4(12.9)$ & $105(27.9)$ \\
Pulmonary tuberculosis & $136(39.3)$ & $16(51.6)$ & $152(40.3)$ \\
Acute severe asthma & $59(17.1)$ & $1(3.2)$ & $60(15.9)$ \\
AECOPD & $27(7,8)$ & $4(12.9)$ & $31(8.2)$ \\
Pleural effusion & $16(4.6)$ & $1(3.2)$ & $17(4.5)$ \\
Bronchogenic CA & $1(0.3)$ & $5(16.1)$ & $6(1.6)$ \\
Pulmonary Embolism & 6 & 0 & $6(1.6)$ \\
Total & $346(91.8)$ & $31(8.2)$ & $377(100)$ \\
\hline
\end{tabular}

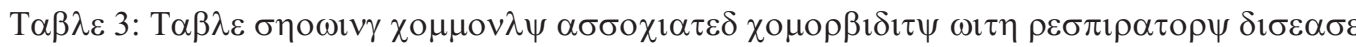

\begin{tabular}{lllll}
\hline Diagnosis & HIV/ AIDS (\%) & DM (\%) & Malignancy (\%) & Total (\%) \\
\hline Pneumonia & $16(16.5)$ & $11(64.7)$ & - & $27(27.9)$ \\
Pulmonary tuberculosis & $72(74.2)$ & $5(29.4)$ & - & $77(40.3)$ \\
Acute severe asthma & $7(7.2)$ & $1(5.9)$ & - & $8(6.8)$ \\
AECOPD & $1(1.0)$ & $4(12.9)$ & 1 & $2(1.7)$ \\
Pleural effusion & $1(1.0)$ & $0(0)$ & 3 & $4(3.4)$ \\
Total & 97 & 17 & 4 & $118(100)$ \\
\hline
\end{tabular}

